\title{
Approaching tipping points: a focussed review of indicators and relevance to managing intertidal ecosystems
}

L Eslami-Andergoli $^{1}$, PER Dale ${ }^{1}, \mathrm{JM}_{\text {Knight }}{ }^{2}, \mathrm{H} \mathrm{McCallum}^{1}$

${ }^{1}$ Environmental Futures Research Institute and Griffith School of Environment, Griffith University, Nathan, Queensland, Australia

${ }^{2}$ Australian Rivers Institute and Griffith School of Environment, Griffith University, Nathan, Queensland, Australia

Corresponding author:

PER Dale

P.dale@griffith.edu.au

$+61418885336$

+6137356717

\begin{abstract}
Abrupt ecosystem regime shifts from one state to another can occur in response to environmental change (such as climate/sea level change). Detecting an approaching tipping point may help management to adapt to or mitigate the effects of catastrophic change. Intertidal wetlands are one of the most vulnerable ecosystems, faced with climate, sea level and anthropogenic changes. Early warning indicators of regime shifts that may be evident include slowing recovery rates from perturbation, increased autocorrelation and variance, changing skewness and self-organised patchiness. We examine these indicators using intertidal examples and discuss the limitations. Managers cannot adapt to or mitigate the effects of state shifts over tipping points if there is no way to detect early warning signals. This detection is
\end{abstract}


highly dependent on system-specific modelling and requires understanding of alternate stable states theory and its application in large, complex ecosystems.

Key words: tipping point indicators; catastrophic change; state change; ecosystem modelling; intertidal wetlands; management 


\section{Introduction}

Abrupt ecosystem regime shifts are expected to become more common as both climate change and depletion of natural resources accelerate (Bestelmeyer et al. 2011a). These shifts are often called tipping points: ecological thresholds beyond which the system may enter unforeseen and unwelcome alternate states, which may not be reversible (Bestelmeyer et al. 2011a; Laurance et al. 2011). Tipping points can be associated with "fold bifurcations" (see Fig. 1), in which the system has two alternate stable states for a given combination of parameters, although other mechanisms are also possible (Hastings and Wysham, 2010). The system can be flipped from one stable state to the other either by gradual changes in parameters or by a pulsed perturbation to the state (Scheffer et al. 2001; Beisner et al. 2003). Alternate stable state dynamics can easily be confused with other types of temporal variability such as regular long-periodic dynamics in a longer time series. Thus, it is important that each system is experimentally analysed to identify both its potential for bi-stability and the conditions for and the specific mechanisms behind alternate stable states (Schroder et al. 2005).

Many systems are subject to abrupt or gradual change that may lead to a tipping point. Examples include desertification and alternate stable states for example in semi arid environments (Rietkerk and van de Koppel 1997; Rietkerk et al. 1997) and modelled by (Dakos et al. 2011). Scheffer et al. (1993) examined alternate states in the eutrophication of shallow lakes (Scheffer et al. 1993). Effects are not limited to terrestrial systems and (Gruber 2011) discussed the irreversibility of ocean warming, 
acidification and deoxygenation at the time scale of centuries. Scott et al. (2008) modeled oceanic circulation responses to climate, noting the possibility of collapse similar to a simple bifurcation; (Longworth et al. 2005) also investigated aspects of ocean circulation and considered the possibility of abrupt climate change associated with shutdown of the thermohaline circulation. These are all examples of likely tipping point situations.

Intertidal wetlands have been recognised as important ecosystems for many decades. As well as their intrinsic value they provide a wide range of ecosystem services of value to people (Kirwan and Megonigal 2013), contributing to human health Dale and Connelly (2012). However, as noted by Laurance et al. (2011), they are globally one of the most threatened ecosystems in coastal locations. They are exposed to change from sea level, climate and the impact of human activity and whether they survive may depend on human management and the socio-economic factors that affect use of adjacent uplands (Dale et al. 2013; Kirwan and Megonigal 2013). To minimise negative impacts and facilitate sustainable management, it is important to be able to predict abrupt changes of state or gradual changes of state, for example in vegetation, that reflect underlying habitat process changes. This may allow managers time to adapt to or mitigate the effects of such changes. Figure 1 simplifies the two common approaches to state changes: one is a response to a sudden large external force leading to a rapid change; the other is a gradual change from one stable state through a period of instability until a new state is reached. The start and end states are different in both cases. 


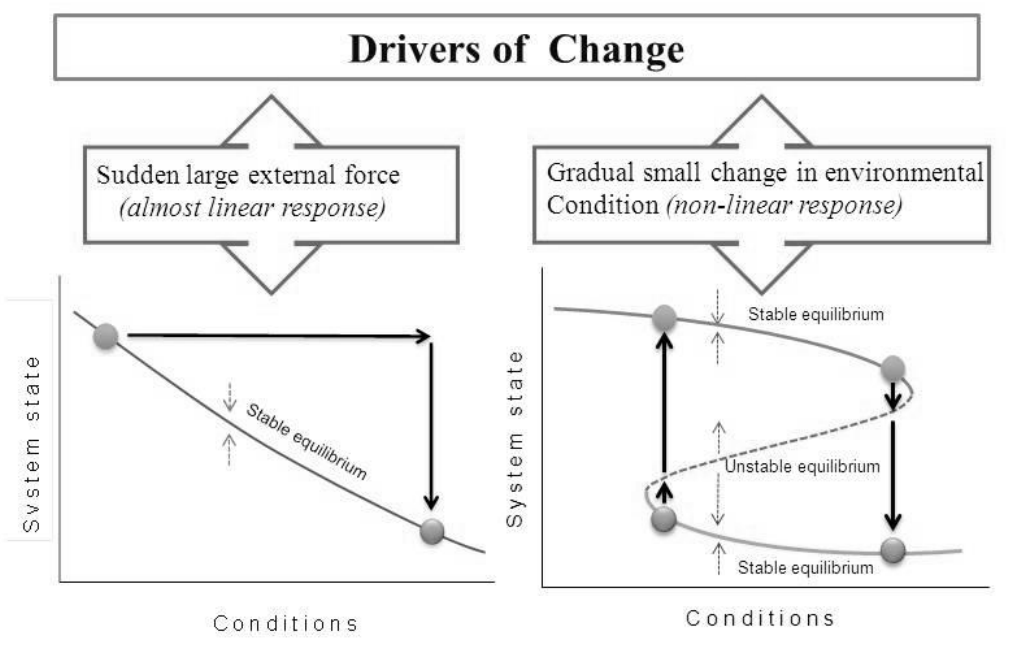

Fig. 1 Tipping points: drivers and mechanisms showing linear and nonlinear changes

Here we review and summarise the characteristics of critical transitions in ecosystems and the early warning indicators of regime shifts. We then illustrate and comment on the concepts in the context of intertidal ecosystems. Using intertidal saltmarsh data from a long-term research project (1985-2005 see Dale 2008) and extended to 2013, we examine potential early warning indicators of a state shift from saltmarsh to mudflat and to mangroves. We discuss the indicators of approaching change and suggest, as ways forward, retrofitting data from existing long-term studies, using remote sensing methods to predict impending ecosystem shift, and palaeoecological data to reconstruct and explain the longer-term history of change. Management responses to approaching tipping points are considered.

\section{Critical transition and early warning signals}


Abrupt ecosystem change can be a result of either approximately linear responses to abrupt changes in pressures, or of non-linear dynamics. Thus, the existence of abrupt change is a necessary condition to demonstrate alternate stable states but on its own it is insufficient to prove their existence (Andersen et al. 2009). In systems that experience sudden external forces, the change will be difficult if not impossible to predict. From a practical perspective the following sections focus on the gradual change situation, which may allow time for managers to respond.

In systems with alternate stable states that are experiencing gradual change, critical thresholds for transitions from one stable state to another correspond to bifurcations, leading to large changes in the behaviour of the system (Strogatz, 1994). The shifts that occur when systems pass bifurcations are referred to as critical transitions (Scheffer et al. 2009). This is shown on the right in Fig 1. There are several types of bifurcation relevant to ecological systems (for more detail see Rinaldi and Scheffer 2000). As a bifurcation is approached, a phenomenon known as "critical slowing down" (CSD) occurs (Strogatz 1994). The questions we address here are whether and how CSD may be detected in intertidal ecosystems and if it can be used to give advance warning of a tipping point, enabling management intervention to prevent undesirable change, or to mitigate the effect of the change. This necessarily involves managing not only ecosystems but also the human environment.

\section{Early warning indicators of impending regime shift}

Critical slowing down occurs in most non-linear transitions when the drivers of the regime shift are gradual (Carpenter et al. 2011). Signals that can be either totally or partially explained by critical slowing down are slower recovery rates, an increase in autocorrelation and an increase in the variance of the system's state variable. Other 
potential warning signals that may be detected in the pattern of fluctuations as a bifurcation is approached are changes in the patterns of skewness and self-organized patchiness. These are discussed in the following sections, including commenting on their relevance to intertidal wetlands with specific reference to a saltmarsh system that has experienced gradual change, leading to a change of state in parts of the system.

Slower recovery rate

Phase transitions may be preceded by periods of slower recovery from small perturbations - the critical slowing down phenomenon (Scheffer and Carpenter 2003; Van Nes and Scheffer 2007; Scheffer et al. 2009; Bailey 2011). This typically starts well before the bifurcation point, and recovery rates decrease monotonically to zero as the critical tipping point is approached (Van Nes and Scheffer, 2007). Dakos et al. (2011) suggest the recovery time required for the system to return to equilibrium after a disturbance is a robust indicator of critical slowing down.

In an intertidal wetland the habitats respond to the interaction of both terrestrial and marine influences. They are dynamic and changes in, for example, plant species distribution, may be simply linear such as in the zoning along the intertidal slope as described by Krauss et al. (2010). They also noted intertidal vulnerability to sea level rise, implying changes that could become non-linear and lead to tipping points, though not using the term. It is obvious that a state change can occur if sea level rises such that the tidal regime no longer satisfies conditions for mangrove growth and survival. This could be evidenced by slower recovery from stressors (e.g., storm damage, insect attack) and culminate in death, which is a change of state. 
Increase in autocorrelation

Increase in temporal and spatial auto-correlation of the state variables of the system are indicators of critical slowing down (Dakos et al. 2008, 2010; Scheffer et al. 2009). However, the resolution of the spatial and temporal processes which operate in the landscape are important and limiting factors (Dakos et al. 2010). In time series data, when the intrinsic rate of change in the system is decreasing, the state of the system at any given time becomes more similar to its previous state, and this is reflected as an increase in short-term auto-correlation in the time series (Dakos et al. 2008). The use of spatial patterns may help to improve the diagnosis of early warning signals as they contain more information than a single data point in a time-series (Guttal and Jayaprakash 2009). This is illustrated in Dakos et al. (2010) and Fernandez and Fort (2009).

In the intertidal context this could be demonstrated by monitoring the system or its relevant variables. It can be indicated by state changes, slower rates of growth or of decreasing plant density. For example, in the sub tropical saltmarsh study Dale and Dale (2002) classified states of the vegetation over a 14-year period, using a transition matrix to identify types of change. They identified a dynamic process whereby samples changed between states but that for some there was a point of no return from a mixed class of Sporobolus virginicus (L.) Kunth and Sarcocornia quinqueflora (Bunge ex Ung.-Sternb.) to a monospecific stand of Sarcocornia. In retrospect this may have been a tipping point. Over the full 28-year period of the study there has been a gradual reduction in the dominant grass (Sporobolus virginicus), culminating in bare ground (mud) from which there has been no return, even after 28 years (Dale et al. unpublished data). Figure 2 illustrates the longer-term changes in Sporobolus density as well as showing the variance (see next section) for selected representative 
sample sites. At the start in 1985 Sporobolus occupied all 30 quadrats; in 2013 it remained in only four quadrats, indicating a relatively widespread change of state.
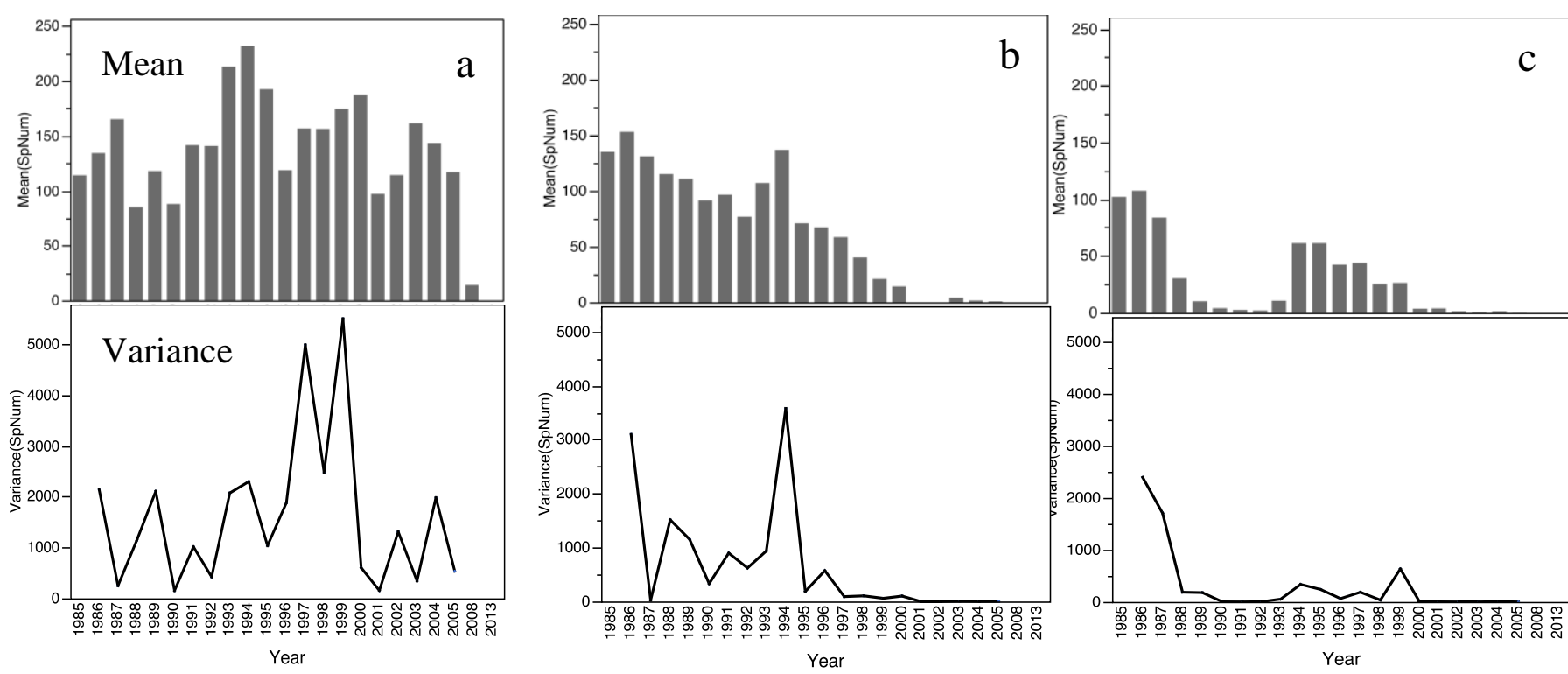

Fig. 2 Mean values and variances for Sporobolus virginicus density in selected $1002 \mathrm{~cm}$ quadtats

Increase in variance

The variance of state variables just prior to a regime shift can exhibit an increase due to increasing temporal fluctuations in the state variable (Carpenter and Brock 2006; Brock et al. 2008; Biggs et al. 2009). Mathematically, the increase in variance occurs because the variance of the state variable/s is inversely proportional to the return rate of the system, and because the return rate approaches zero at the critical point (Brock and Carpenter 2010). As the system approaches the bifurcation point, its variance power spectra (i.e., the Fourier transform of the time series) shift to a lower frequency. However, ecological time series data are often too sparse to estimate 
spectral shifts and may consequently not provide sufficient resolution for detecting changes (Carpenter and Brock 2006).

In theory, increased variance is an important signal of regime shift, but in practice, changes in variance due to impending regime shifts may be difficult to distinguish from other drivers of variance such as exogenous noise that affects the ecosystem (Carpenter and Brock 2006). In addition, variance may be either dampened or amplified near critical thresholds in complex systems (Brock and Carpenter 2010). Recently Dakos et al. (2012) indicated that variance may decrease close to a transition. Thus, the variance in an indicator variable close to a transition is a less generic indicator of critical slowing down than auto-correlation in time series data (Dakos et al. 2012). Nevertheless there is some limited empirical support for using variance as an early indicator of change especially in complex systems (Cottingham et al. 2000; Litzow et al. 2008; Carpenter et al. 2011; Veraart et al. 2011).

In the intertidal context McGlathery et al. (2013) note that marsh and mudflats occupy alternate stable states, largely related to marine influences. However, within a saltmarsh there may, at the microscale (metres), be comparable alternate states driven by processes within the marsh. Using the long-term data referred to above the variance as sites approach a change from Sporobolus to a bare ground (mud) state can be checked. Figure 2 shows several patterns of variance in the density of Sporobolus over 28 years for some sample sites. Fig. 2a shows a sharp increase in variance after 1995, followed by a decrease, but plant density was zero only for the last year surveyed (2013). This late change of state (to mud) does not clearly indicate that a tipping point has been passed. In contrast, Fig. $2 b$ shows an increase in variance around 1992 that was followed by a reduction in plant density leading to a bare mud state that has continued since 1995 . This could indicate a very local tipping point had 
been reached. Figure 2c shows a decline in Sporobolus density, followed by a small recovery and then, after a sharp rise in variance, the bare mud became the state. Thus variance, as indicated in the literature, may indicate an impending change of state, but this may not always be so.

\section{Changing skewness}

Changes in the pattern of skewness over time of the state variable as the system approaches a tipping point is a model-independent indicator of regime shift suggested by Guttal and Jayaprakash (2008). However, if the regime shift occurs rapidly measures of changing asymmetry are not useful because the skewness reflects the regime shift itself rather than being an early indicator of it. In addition, changes in asymmetry can also arise from asymmetry in exogenous noise. As an example see Guttal and Jayaprakash (2009).

In the intertidal context this is demonstrated for 20 years of the saltmarsh data by the distributions in Fig. 3 (between 1985-2005, every four years). Figure 3 shows increasing skewness over time for the study area. In part this reflects the reduction in density of the plants, but, towards the later stages, the increasing skew also reflects the combination of both pre and post regime shift states in the data.
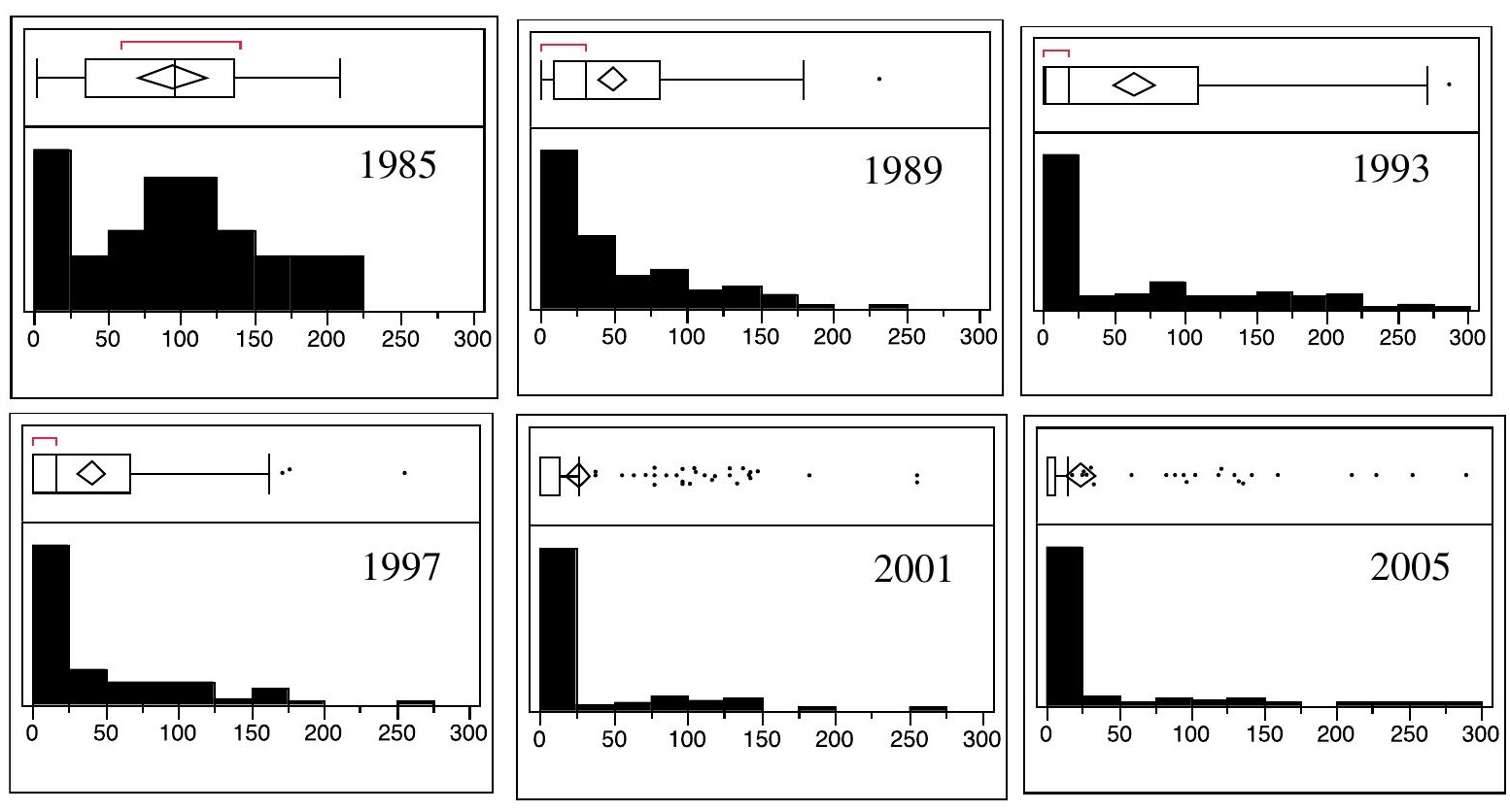
Fig. 3 Demonstrating increasing skewness in a subtropical intertidal saltmarshdata distribution and boxplots for the density of Sporobolus virginicus over 20 years. Note the $\mathbf{x}$ axis scales vary: the nature of the distribution is the focus

Self-organized patchiness

A growing number of studies link self-organized patchiness to catastrophic shifts between ecosystem states (Von Hardenberg et al. 2001; Rietkerk et al. 2004; Kefi et al. 2007a; Kefi et al. 2007b). Patchy ecosystems are often characterised by dynamic non-linear behaviour, and sudden catastrophic shifts from heterogeneous to homogeneous landscape states may occur in response to external stresses (Rietkerk et al. 2004). Hence, it has been suggested that predictable forms of self-organized patchiness could be used as indicators of imminent catastrophic shifts in ecosystem state (Rietkerk et al. 2004). For further discussion refer to Schoelynck et al. (2011) and Rietkerk and van de Koppel (2008) who found the approach useful and to Kefi et al. (2007a) who did not.

Another property of the spatial self-organized pattern is scale invariance and associated long-range correlations of organism distribution. These are characterized by power law relationships that emerge before the transition, due to short-range interactions (Pascual and Guichard 2005). In contrast, two independent studies by Moreno-De las Heras et al. (2011) and Maestre and Escudero (2009) suggested that deviations from power-law model predictions were not universal indicators of the loss of ecosystem integrity.

It is still unclear whether systems with self-organized patchiness display critical slowing down or not, and the applicability of this indirect indicator of critical slowing 
down as an early warning signal of a catastrophic ecosystem shift remains largely an open question for further investigation (Dakos et al. 2010).

In the intertidal context the scale at which spatial patterns are significant is important in forewarning of a shift. Many factors are important, including the role of vegetation as systems respond to sea level change (see Krauss et al. 2014). In our saltmarsh example vegetation patterns occurred at a level of resolution of meters and were related to tidal regimes and their interaction with micro-topography. The 14-year analysis referred to in Dale and Dale (2002) showed that sample sites' behaviour varied and the cumulative effect was for vegetation patches (samples) to increasingly become different from each other in the proportion of the two plant species. The situation is similar in the mangrove-saltmarsh interface as mangroves encroach onto and replace saltmarsh thereby creating mangrove patches while destroying saltmarsh ones (Eslami-Andergoli et al. 2009). In that context the state change from marsh to mangrove has implications for aspects of management especially for disease vector mosquitoes. This was discussed in Dale et al. (2013).

\section{Synthesis and Discussion}

The indicators discussed above have been tested in various ecosystems and at various spatial and temporal scales, including; aquatic food webs (Carpenter et al. 2011), single species population studies (Drake and Griffin 2010; Veraart et al. 2011), fisheries (Litzow et al. 2008) and over geological time scales (Dakos et al. 2008). These are summarised in Table 1 with comments on their potential application to intertidal habitats. 


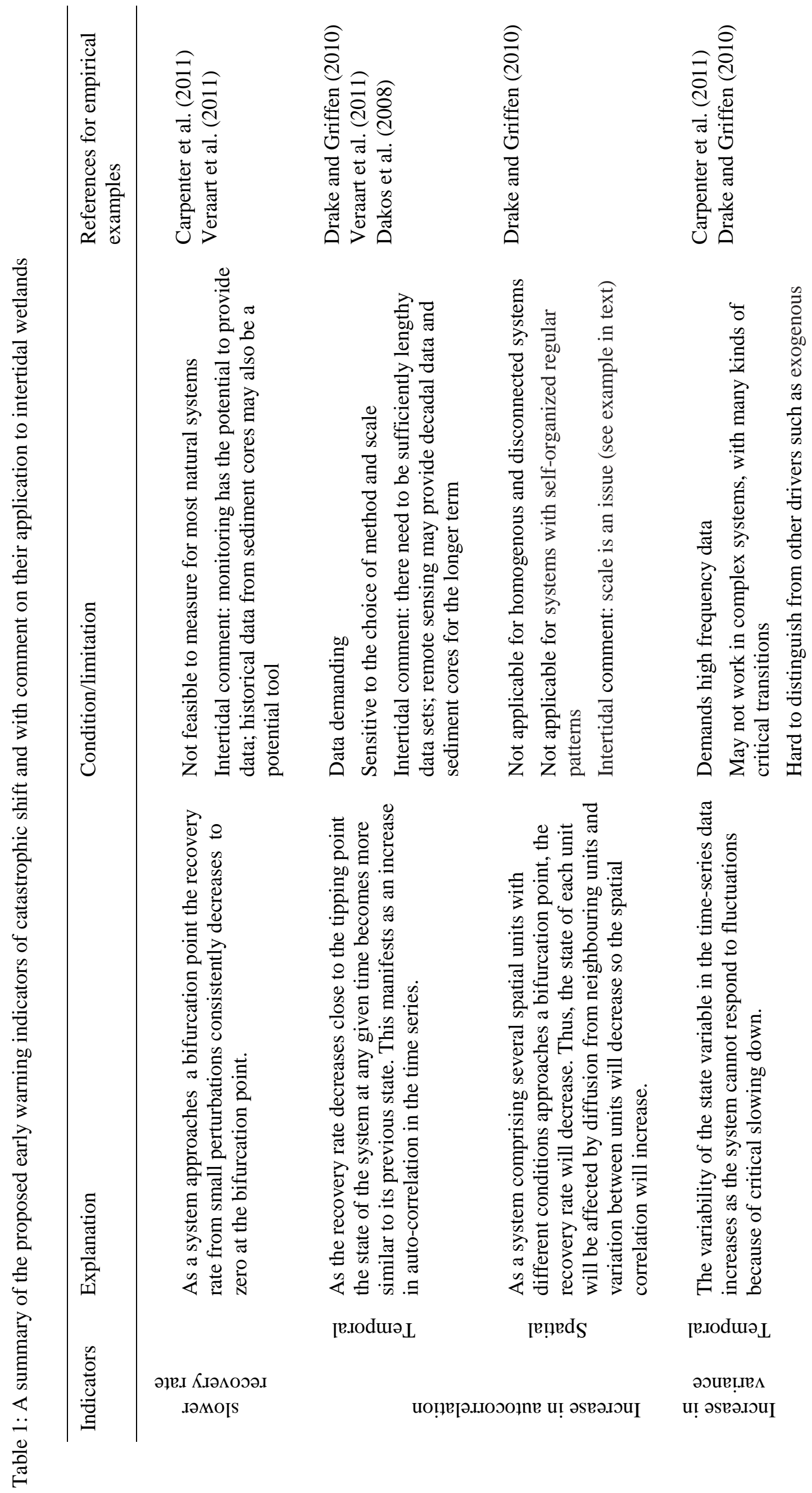




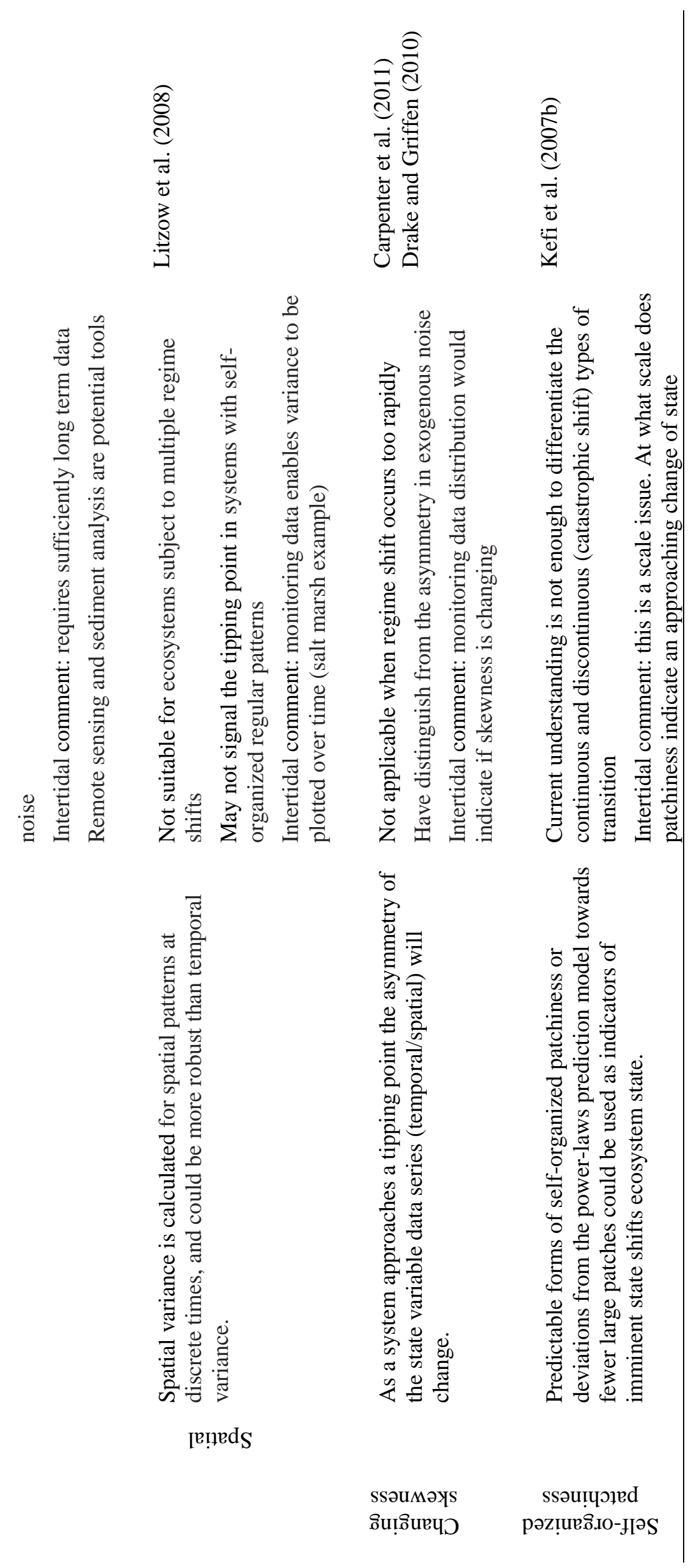




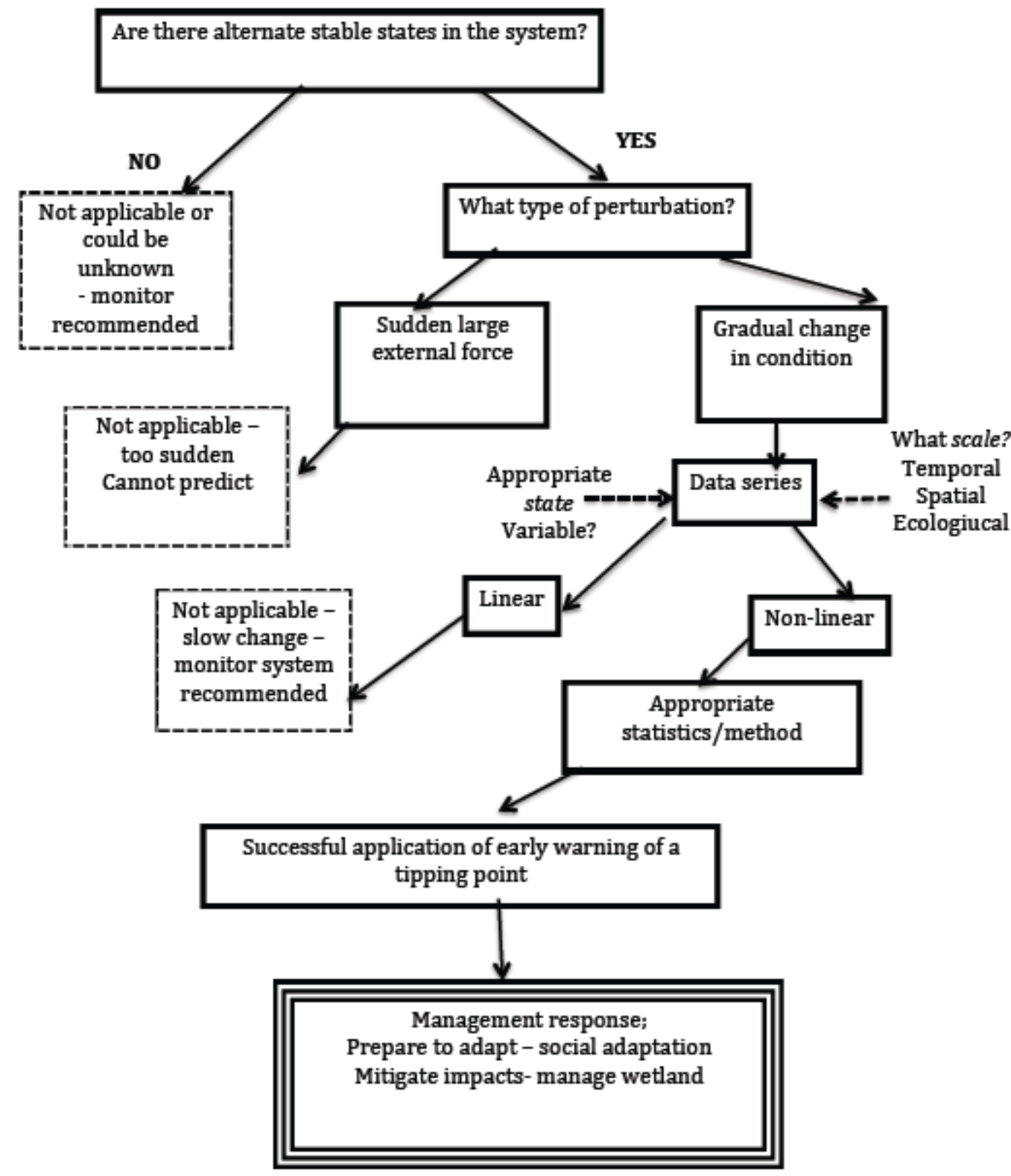

Fig. 4 How to get there: a road map to move towards identifying and responding to a tipping point

Most of the proposed indicators are derived from models of simple ecosystems and empirical evidence for them is not common (Scheffer et al. 2009). The saltmarsh system referred to above was comprised of only two species (Sporobolus and Sarcocornia). In more temperate saltmarshes the species diversity is much greater and our simple analysis would not be feasible. There are also several reasons why 
indicators may not indicate impending transitions in real ecosystems including: (1) insufficient data or data at too coarse a resolution to adequately identify ecosystem transitions and their associated indicators of slowing down; (2) inaccurate or imprecise observation; (3) occurrence of a sudden large external force that can trigger a shift before the warning can be detected; (4) interactions of multiple thresholds and correlated process errors could obscure the early warning signals; (5) a systematic change in the external perturbation regime over the period leading up to a shift; (6) uncertainty involved in identifying and modelling the dynamic processes and (7) the proposed early warning signals may not be detectable in some kinds of critical transitions, such as global bifurcations (Kleinen et al. 2003; Carpenter and Brock 2006; Carpenter et al. 2008; Guttal and Jayaprakash 2008; Biggs et al. 2009; Contamin and Ellison 2009; Scheffer et al. 2009; Brock and Carpenter 2010; Hastings and Wysham 2010; Dakos et al. 2011). Furthermore, there is always an underlying unpredictability in the system, as critical transitions can be triggered by stochastic shocks while the system is approaching bifurcation point (Veraart et al. 2011).

As intertidal wetland systems (saltmarsh and mangroves) are threatened ecosystems and are foci of management it is important to explore the potential applicability of methods that would overcome the issue of data both for temporal and spatial analysis. Temporal indicators require long time-series of relatively frequent observations, whereas spatial indicators could be useful even if measurements are irregular or infrequent over time (Carpenter and Brock 2010). To address temporal data limitations monitoring needs to be carried out over as long a time frame as is practicable and as far possible relevant to ecological processes. This may be based on field observations or may use remote sensing.

Data from other research may be suitable for assessing tipping point early warning indicators as a retrofitting exercise. As a field based method, the long-term (28-year 
monitoring) saltmarsh analysis referred to above yielded potentially useful information about processes of change at the micro level (meters) and could be used to demonstrate some of the early warning indicators identified in the literature. However, retrofitting data does not necessarily imply a shift has occurred in the system, though change undoubtedly has occurred in our example.

For more general assessment there is a variety of remote sensing instruments (satellite, airborne) that can yield data at various spatial scales and comparable over different periods of time (e.g., in Australia from 1940s onwards for aerial and from 1972 for satellite) for detecting and monitoring change in ecosystems. Remote sensing can help in identifying early indicators of tipping points because selected wavebands, for example the near infrared, are sensitive to vegetation condition, which is indicative of the state of the vegetation. This was exemplified, using aerial photography for the saltmarsh example by Dale et al (1986) and Jones et al. (2004). Recently Fuller and Yang (2014) used satellite imagery and the Normalized Difference Vegetation Index (NDVI - a relationship between near infra-red and red wavelengths) to monitor quite detailed change in the Florida Everglades with 46 images per year (2001 -2008). Remote sensing can provide consistent measurements of landscape condition, and the opportunity for detecting both abrupt and slow trends in change over time and further insights to the stressors and drivers of the change (Kennedy et al. 2009). The data allows research at multiple spatial scales and the investigation of regime shifts at multiple scales in any ecosystem. Bestelmeyer et al. (2011a) suggested that multi-scaled study at the level of landscape, site and patch might be useful, as state transitions may happen at a fine scale and then gradually accumulate (as may be happening in the saltmarsh example), or extend to a broader scale from points of initial impacts. 
For excavating the historical/geological history of change to search for tipping points, field based assessment of substrate cores and analysis of composition (palaeo records) has potential. It can reconstruct past environments and identify change, although there are data limitations for this too. In palaeoecological studies, there are several methods including pollen and stable isotope analysis, core chronology and stratigraphic characterisation that can be used to illustrate vegetation dynamics and the environmental history of coastal wetlands (Ellison 2008; Monacci et al. 2009; Watson et al. 2011). As an example, the cluster analysis of pollen by Dale et al. (2010) identified recurring patterns of clusters of classes over thousands of years with some clusters apparently becoming extinct and replaced by different assemblages. Whether the change was linear or non-linear is not clear, but it does illustrate how data may be recycled for another purpose (always on condition that it is suitable). A palaeoecological approach will be further explored in another paper.

\section{Management implications}

Predicting the likelihood of critical transitions is important for directing management actions, especially in intertidal wetlands, as regime shifts can have significant ecological, social and economic impacts (Biggs et al. 2009). However, the empirical evidence of early warning signals of impending regime shifts and their application to resource management is still lagging behind theory. Recent research has focused on developing indicators of regime shifts, without determining how much advance warning these indicators may provide and whether they allow time to manage an ecosystem towards a desired regime (Contamin and Ellison 2009), or if it is possible. For example, when response variables are affected by broad-scale physical drivers, 
such as sea level rise in intertidal wetlands, direct intervention in the ecosystem itself is not feasible. In such situations, forecasting and adaptation methods could be developed (Bestelmeyer et al. 2011b) to manage human responses - defend, retreat, adapt. In summary, although early warning indicators of regime shifts are crucial for managing transitions in real ecosystems, they are still elusive and their application is largely untested (Dakos et al. 2010). This is an important knowledge gap in one of the most threatened ecosystems: intertidal wetlands.

Finally a 'road map' is shown in Figure 3 to navigate the tipping point issue. It shows that, where processes are unknown or linear (left side of the 'map'), then monitoring of appropriate variables is needed. For managers that may be outside the scope of their work environment or their capacity. However, in simple systems with relatively slow change, having appropriate information may allow managers to plan to adapt or to mitigate the effects of a state change, with options such as discussed in Dale et al (2013) for mangrove incursion into saltmarsh.

\section{Conclusion}

Further development of early-warning signals and their successful application in real ecosystems requires a deeper understanding of alternate stable states theory than is currently available. A combined approach of careful ecosystem modelling, detailed temporal and spatial data from field investigation and non-linear statistical techniques is required. Challenges of model identification and statistical estimation still limit the ability to detect generic indicators of impending regime shift and produce a probabilistic forecasting framework. This is a difficult task as ecosystem processes are usually governed by mechanisms that occur at different scales of space, time and ecological organization. Furthermore, because several drivers can cause catastrophic 
shifts in an ecosystem, it is essential that multiple variables are tracked simultaneously for long periods of time. Also, long-term observations, comparisons of ecosystems across gradients of key drivers, and appropriately scaled experiments are essential to warn of impending regime shift. Retrofitting data from pre-existing experiments - especially long-term studies - can be a useful approach for tracking ecosystem regime shifts and it would be useful to consider the possibility of regime shifts when designing ecological studies.

Currently, predicting the actual moment of the tipping point in real ecosystems is out of reach, but several indices including, shifts in symmetry, variance, autocorrelation, patchiness and recovery rates, can serve as a warning. Recent technology advances such as in remote sensing and palaeoecology could facilitate progress in this area in an innovative way.

However there remains a barrier for managers in the context of the sort of change that a tipping point will produce. Even if the science is addressed it must be communicated between researchers and managers and so there needs to be an effective plan with feasible actions to deal with change.

\section{Acknowledgements}

We thank the reviewers for their constructive comments on the manuscript. We acknowledge support from an Innovative Research Universities of Australia Tipping Point project.

\section{References}


Andersen T, Carstensen J, Hernández-Garcí E, Duarte CM (2009) Ecological thresholds and regime shifts: Approaches to identification. Trends Ecol Evol 24: 49-57.

Bailey R (2011) Spatial and temporal signatures of fragility and threshold proximity in modelled semi-arid vegetation. P Roy Soc Lond B Bio 278: 1064-1071.

Beisner BE, Haydon DT, Cuddington K (2003) Alternative stable states in ecology. Front Ecol Environ 1: 376-382.

Bestelmeyer BT, Goolsby DP, Archer SR (2011a) Spatial perspectives in state and transition models: A missing link to land management? J Appl Ecol 48, 746-75.

Bestelmeyer BT. Ellison AM, Fraser WR, Gorman KB, Holbrook SJ, Laney CM, Ohman MD, et al. (2011b). Analysis of abrupt transitions in ecological systems. Ecosphere 2: art 129, doi:10.1890/ES11-00216.1.

Biggs R, Carpenter SR, Brock WA (2009) Turning back from the brink: Detecting an impending regime shift in time to avert it. Proc Natl Acad Sci USA 106: 826-831.

Brock WA, Carpenter S (2010) Interacting regime shifts in ecosystems: Implication for early warnings. Ecol Monogr 80: 353-367.

Brock WA, Carpenter SR, Scheffer M (2008) Regime shifts, environmental signals, uncertainty, and policy choice. In: Norberg, J. \& Cumming, G.S. (Eds.); Complexity theory for a sustainable future. Columbia University Press, New York, New York, USA, pp. 180-206.

Carpenter S, Brock W (2006) Rising variance: A leading indicator of ecological transition. Ecol Lett 9: 311-318.

Carpenter S, Brock W, Cole J, Kitchell J, Pace M (2008) Leading indicators of trophic cascades. Ecol Lett 11: 128-138. 
Carpenter S, Cole J, Pace M, Batt R, Brock W, Cline T, Coloso J, Hodgson J, Kitchell J, Seekell D (2011) Early warnings of regime shifts: A whole-ecosystem experiment. Science 332: 1079 - 1082.

Carpenter SR (2005) Eutrophication of aquatic ecosystems: Bistability and soil phosphorus. Proc Natl Acad Sci USA 102: 10002-10005.

Carpenter SR, Brock WA (2010) Early warnings of regime shifts in spatial dynamics using the discrete Fourier transform. Ecosphere 1:art10, doi:10.1890/ES1000016.1.

Chisholm RA, Filotas E (2009) Critical slowing down as an indicator of transitions in two-species models. J Theor Biol 257, 142-149.

Choi JS, Frank KT, Leggett WC, Drinkwater K (2004) Transition to an alternate state in a continental shelf ecosystem. Can J Fish Aquat Sci 61:505-510

Contamin R, Ellison AM (2009) Indicators of regime shifts in ecological systems: What do we need to know and when do we need to know it. Ecol Appl 19: 799816.

Cottingham KL, Rusak JA, Leavitt PR (2000) Increased ecosystem variability and reduced predictability following fertilisation: Evidence from palaeolimnology. Ecol Lett 3: 340-348.

Dakos V, Kefi S, Rietkerk M, van Nes EH, Scheffer M (2011) Slowing down in spatially patterned ecosystems at the brink of collapse. Am Nat 177: E153-E166.

Dakos V, Scheffer M, Van Nes EH, Brovkin V, Petoukhov V, Held H (2008) Slowing down as an early warning signal for abrupt climate change. Proc Natl Acad Sci USA 105: 14308-14312.

Dakos V, van Nes EH, D'Odorico P, Scheffer M (2012) Robustness of variance and autocorrelation as indicators of critical slowing down. Ecology 93: 264-271. 
Dakos V, van Nes EH, Donangelo R, Fort H, Scheffer M (2010) Spatial correlation as leading indicator of catastrophic shifts. Theor Ecol 3: 163-174.

Dale MB, Allison, L, Dale PER (2010) Model Selection using Minimal Message Length: an example using pollen data, Community Ecol 11(2): 187-201

Dale PER (2008) Assessing impacts of habitat modification on a subtropical salt marsh: 20 years of monitoring. Wetl Ecol Manag 16: 77-87 DOI 10.1007/s11273007-9058-2

Dale PER, Eslami-Andergoli L, Knight JM. (2013) The impact of encroachment of mangroves into saltmarshes on saltwater mosquito habitats. J Vect Ecol 38(2): 330-338.

Dale PER and Dale MB (2002) Optimal classification to describe environmental change: pictures from the exposition. Community Ecol: 3: 19-29.

Dale PER, Hulsman K, Chandica AL (1986) Classification of Reflectance on Color Infrared Aerial Photographs and Subtropical Salt-Marsh Vegetation Types. Int J Remote Sens 7:1783-1788.

de Young B, Barange M, Beaugrand G, Harris R, Perry RI, Scheffer M, Werner F (2008) Regime shifts in marine ecosystems: Detection, prediction and management. Trends Ecol Evol 23: 402-409.

Ditlevsen PD, Johnsen SJ (2010) Tipping points: Early warning and wishful thinking. Geophys Res Lett 37, L19703, doi:10.1029/2010GL044486.

Drake JM, Griffen BD (2010) Early warning signals of extinction in deteriorating environments. Nature 467: 456-459.

Ellison JC (2008) Long-term retrospection on mangrove development using sediment cores and pollen analysis: A review. Aquat Bot 89: 93-104. 
Eslami-Andargoli L, Dale PER, Sipe N, Chaseling J (2009) Mangrove expansion and rainfall patterns in Moreton Bay, southeast Queensland, Australia. Estuar Coast Shelf Sci 85: 292-298.

Fernandez A, Fort H (2009) Catastrophic phase transitions and early warnings in a spatial ecological model. J Stat Mechanics: Theory and Experiment 2009: doi:10.1088/1742-5468/2009/09/P09014.

Foley JA, Coe MT, Scheffer M, Wang G (2003) Regime shifts in the Sahara and Sahel: Interactions between ecological and climatic systems in northern Africa. Ecosystems 6: 524-532.

Frank KT. Petrie B, Choi JS, Leggett WC (2005) Trophic cascades in a formerly coddominated ecosystem. Science 308: 1621-1623.

Fuller D, Yang Y (2014) Recent Trends in Satellite Vegetation Index Observations Indicate Decreasing Vegetation Biomass in the Southeastern Saline Everglades Wetlands. Wetlands 34:66-77.

Gruber N (2011) Warming up, turning sour, losing breath: ocean biogeochemistry under global change. Philos T R Soc A 369 (1943):1980-1996.

Guttal V, Jayaprakash C (2008) Changing skewness: An early warning signal of regime shifts in ecosystems. Ecol Lett 11, 450-460.

Guttal V, Jayaprakash C (2009) Spatial variance and spatial skewness: Leading indicators of regime shifts in spatial ecological systems. Theor Ecol 2: 3-12.

Handa I, Harmsen R, Jefferies R (2002) Patterns of vegetation change and the recovery potential of degraded areas in a coastal marsh system of the Hudson Bay lowlands. J Ecol 90: 86-99.

Hastings A, Wysham DB (2010) Regime shifts in ecological systems can occur with no warning. Ecol Lett 13: 464-472. 
Jones J, Dale PER, Chandica AL, Breitfuss MJ (2004) Changes in the distribution of the grey mangrove Avicennia marina (Forsk.) using large scale aerial color infrared photographs: are the changes related to habitat modification for mosquito control? Estuar Coast Shelf S 61:45-54.

Kefi S, Rietkerk M, van Baalen M, Loreau M (2007a) Local facilitation, bistability and transitions in arid ecosystems. Theor Popul Biol 71: 367-379.

Kefi S, Rietkerk M, Alados CL, Pueyo Y, Papanastasis V P, El Aich A, de Ruiter PC (2007b) Spatial vegetation patterns and imminent desertification in Mediterranean arid ecosystems. Nature 449: 213-217.

Kefi S, Rietkerk M, Roy M, Franc A, De Ruiter PC, Pascual M (2011) Robust scaling in ecosystems and the meltdown of patch size distributions before extinction. Ecol Lett 14: 29-35.

Kennedy RE, Townsend PA, Gross JE, Cohen WB, Bolstad P, Wang YQ, Adams P (2009) Remote sensing change detection tools for natural resource managers: Understanding concepts and tradeoffs in the design of landscape monitoring projects. Remote Sens Environ 113:1382-1396.

Kirwan ML, Megonigal JP (2013) Tidal wetland stability in the face of human impacts and sea-level rise. Nature 504:53-60

Kleinen T, Held H, Petschel-Held G (2003) The potential role of spectral properties in detecting thresholds in the earth system: Application to the thermohaline circulation. Ocean Dynam 53: 53-63.

Krauss KW, Cahoon DR, Allen JA, Ewel KC, Lynch JC, Cormier N (2010) Surface Elevation Change and Susceptibility of Different Mangrove Zones to Sea-Level Rise on Pacific High Islands of Micronesia. Ecosystems 13:129-143. 
Krauss KW, McKee KL, Lovelock CE, Cahoon DR, Saintilan N, Reef R, Chen L (2014) How mangrove forests adjust to rising sea level. New Phytologist 202:1934.

Laurance WF, Dell B, Turton SM, Lawes MJ, Hutley LB, McCallum H, Dale P, Bird M, Hardy G, Prideaux G, Gawne B, McMahon CR, Yu R, Hero J, Schwarzkopf L, Krockenberger A, Douglas M, Silvester E, Mahony M, Vella K, Saikia U, Wahren C, Xu Z, Smith B, Cocklin C (2011) The 10 Australian ecosystems most vulnerable to tipping points: Biol Conserv 144: 1472-1480.

Litzow MA, Urban JD. Laurel BJ (2008) Increased spatial variance accompanies reorganization of two continental shelf ecosystems. Ecol Appl 18: 1331-1337.

Longworth H, Marotzke J, Stocker TF (2005) Ocean gyres and abrupt change in the thermohaline circulation: A conceptual analysis. J Climate 18 (13):2403-2416. Maestre FT, Escudero A (2009) Is the patch size distribution of vegetation a suitable indicator of desertification processes? Ecology 90: 1729-1735.

McGlathery KJ, Reidenbach MA, D’Odorico P, Fagherazzi S, Pace ML, Porter JH (2013) Oceanography 26(3): 220-231.

Monacci NM, Meier-Grünhagen U, Finney BP, Behling H, Wooller MJ (2009) Mangrove ecosystem changes during the Holocene at Spanish Lookout Cay, Belize. Palaeogeography, Palaeoclimatology, Palaeoecology 280: 37-46.

Moreno-De Las Heras M, Saco P, Willgoose G, Tongway D (2011) Assessing landscape structure and pattern fragmentation in semiarid ecosystems using patchsize distributions. Ecol Appl 21: 2793-2805.

Pascual M, Guichard F (2005) Criticality and disturbance in spatial ecological systems. Trends Ecol Evol 20: 88-95.

Rietkerk M, Dekker SC, de Ruiter PC, van de Koppel J (2004) Self-organized patchiness and catastrophic shifts in ecosystems. Science 305: $1926-1929$. 
Rietkerk M, van den Bosch F, van de Koppel J (1997) Site-specific properties and irreversible vegetation changes in semi-arid grazing systems. Oikos 80:241-252.

Rietkerk M, van de Koppel J (1997) Alternate stable states and threshold effects in semi-arid grazing systems. Oikos 79:69-76.

Rietkerk M, van de Koppel J (2008) Regular pattern formation in real ecosystems. Trends Ecol Evol 23: 169-175.

Rinaldi, S., Scheffer M (2000) Geometric analysis of ecological models with slow and fast processes. Ecosystems 3: 507-521.

Scheffer M, Bascompte J, Brock WA, Brovkin V, Carpenter SR, Dakos V, Held H, van Nes EH, Rietkerk M, Sugihara G (2009) Early-warning signals for critical transitions. Nature 461: 53-59.

Scheffer M, Carpenter SR (2003) Catastrophic regime shifts in ecosystems: Linking theory to observation. Trends Ecol Evol 18: 648-656.

Scheffer M, Carpenter S, Foley JA, Folke C, Walker B (2001) Catastrophic shifts in ecosystems. Nature 413: 591-596.

Scheffer M, Hosper S, Meijer M, Moss B, Jeppesen E (1993) Alternative equilibria in shallow lakes. Trends Ecol Evol 8: 275-279.

Schoelynck J, de Groote T, Bal K, Vandenbruwaene W, Meire P, Temmerman S (2011) Self-organised patchiness and scale-dependent bio-geomorphic feedbacks in aquatic river vegetation. Ecography: doi: 10.1111/j.1600-0587.2011.07177.x.

Schroder A, Persson L, De Roos AM (2005) Direct experimental evidence for alternative stable states: A review. Oikos 110: 3-19.

Strogatz SH (1994) Nonlinear dynamics and chaos with application to physics, biology, chemistry and engineering. Perseus, New York. pp 248.

Van Nes EH, Scheffer M (2007) Slow recovery from perturbations as a generic indicator of a nearby catastrophic shift. Am Nat 169: 738-747. 
Veraart AJ, Faassen EJ, Dakos V, van Nes EH, Lurling M, Scheffer M (2011)

Recovery rates reflect distance to a tipping point in a living system. Nature: doi:10.1038/nature10723.

Von Hardenberg J, Meron E, Shachak M, Zarmi Y (2001) Diversity of vegetation patterns and desertification. Phys Rev Lett 87: 198101.

Walker B, Meyers JA (2004) Thresholds in ecological and social-ecological systems: A developing database. Ecol Soc 9(2),

3: http://www.ecologyandsociety.org/vol9/iss2/art3/.

Watson EB, Wasson K, Pasternack GB, Woolfolk A, Van Dyke E, Gray AB, Pakenham A, Wheatcroft RA (2011) Applications from paleoecology to environmental management and restoration in a dynamic coastal environment. Restor Ecol 19: 765-775. 